\title{
Knowledge and experience of young people regarding drug abuse, 1969-89
}

\author{
J D Wright, L Pearl
}

Community Long Stay

Unit, Clevelands

Leasowes, Wolverhampton

WV1 4TG

J D Wright, FFCM, consultant in public health medicine

Wolverhampton

Polytechnic

L Pearl, DPHIL, principal

lecturer in statistics

Correspondence to:

Dr Wright.

BrMed f 1990;300:99-103

\begin{abstract}
Objective-To establish a baseline of knowledge to plan an effective health education programme in schools. The survey was repeated at five year intervals from 1969 to 1989.

Design-To preserve consistency, the same anonymous questionnaire, which was confidential to the research workers, was used throughout.

Setting-Three secondary schools in Wolverhampton in different parts of the town and representing different social groups.

Subjects-Sample sizes ranged from 471 fourth year pupils (aged 14 to 15 ) in 1969 to 540 in 1984 and 380 in 1989, the decrease being due mainly to the falling birth rate. There were slightly more girls than boys, and the pupils covered the whole range of academic ability.
\end{abstract}

TABLE I-Knowledge of dangers and methods of taking drugs cited by young people. ${ }^{\star}$ Figures are numbers (percentage) of pupils who cited drug in answer to first question (see appendix)

\begin{tabular}{|c|c|c|c|c|c|c|}
\hline & Cannabis & Opiates & Lysergide & Cocaine & Solvents & Amphetamines \\
\hline \multicolumn{7}{|c|}{ Dangers } \\
\hline \multicolumn{7}{|l|}{ Can kill } \\
\hline 1969 & $60(14)$ & $90(23)$ & $42(12)$ & & & $25(13)$ \\
\hline 1974 & $64(17)$ & $80(25)$ & $27(12)$ & $5(6)$ & & $5(8)$ \\
\hline 1979 & $81(18)$ & $171(35)$ & $54(28)$ & $67(22)$ & $13(26)$ & $6(13)$ \\
\hline 1984 & $80(20)$ & $124(32)$ & $4(9)$ & $77(25)$ & $20(19)$ & $1(10)$ \\
\hline 1989 & $90(30) \dagger$ & $171(52) \dagger$ & $34(24) \dagger$ & $143(48) \dagger$ & $22(35) \ddagger$ & $8(21)$ \\
\hline $95 \%$ Confidence interval $\$$ & 4 to 17 & 13 to 27 & 5 to 27 & 15 to 29 & 2 to 30 & \\
\hline \multicolumn{7}{|l|}{$\begin{array}{l}\text { Can cause mental illness and } \\
\text { hallucinations }\end{array}$} \\
\hline 1969 & $42(10)$ & $31(8)$ & $73(21)$ & & & $5(3)$ \\
\hline 1974 & $59(16)$ & $48(15)$ & $50(23)$ & $6(7)$ & & $8(12)$ \\
\hline 1979 & $44(10)$ & $36(7)$ & $36(19)$ & $15(5)$ & $6(12)$ & $8(17)$ \\
\hline 1984 & $24(6)$ & $20(5)$ & $10(21)$ & $20(7)$ & $6(6)$ & $2(20)$ \\
\hline 1989 & $10(3)$ & $7(2)$ & $30(22)$ & $9(3)$ & $9(14)$ & $6(15)$ \\
\hline \multicolumn{7}{|c|}{ Can cause addiction and dependence } \\
\hline 1969 & & $25(6)$ & $.7(2)$ & & & $4(2)$ \\
\hline 1974 & $47(12)$ & $53(17)$ & $19(9)$ & $7(8)$ & & $5(8)$ \\
\hline 1979 & $31(7)$ & $57(12)$ & $5(3)$ & $14(5)$ & & $0(0)$ \\
\hline 1984 & 44 (11) & $62(16)$ & $9(19)$ & $36(12)$ & $6(6)$ & $0(0)$ \\
\hline 1989 & $52(17) \neq$ & $79(24)+$ & $18(13)$ & $73(24) t$ & $5(8)$ & $4(10)$ \\
\hline $95 \%$ Confidence interval $\$$ & 1 to 12 & 2 to 14 & & 6 to 19 & & \\
\hline \multicolumn{7}{|l|}{$\begin{array}{l}\text { Can cause drowsiness, coma, and } \\
\text { dreaminess }\end{array}$} \\
\hline 1969 & $17(4)$ & $12(3)$ & $10(3)$ & & & $4(2)$ \\
\hline 1974 & $52(14)$ & $28(9)$ & $16(7)$ & $10(12)$ & & 7 (11) \\
\hline 1979 & $56(12)$ & $49(10)$ & 126 & $25(8)$ & $5(10)$ & $4(9)$ \\
\hline 1984 & $67(17)$ & $46(12)$ & 36 & $31(10)$ & $15(14)$ & $4(40)$ \\
\hline 1989 & $35(12)$ & $17(5) t$ & $9(6)$ & $20(7)$ & $6(10)$ & $2(5) \ddagger$ \\
\hline $95 \%$ Confidence interval $\S$ & & -11 to -3 & & & & -66 to -4 \\
\hline Can give you AIDS & & & & & & \\
\hline \multirow{2}{*}{\multicolumn{7}{|c|}{ Screws you up }} \\
\hline & & & & & & \\
\hline 1989 & $2(1)$ & $8(2)$ & $1(1)$ & $2(1)$ & & \\
\hline \multicolumn{7}{|c|}{ Knowledge of correct method of taking drug } \\
\hline 1969 & $325(76)$ & $188(48)$ & $154(44)$ & & & $175(89)$ \\
\hline 1974 & $309(81)$ & $207(66)$ & $83(38)$ & $47(55)$ & & $52(80)$ \\
\hline 1979 & $368(82)$ & $392(79)$ & $61(32)$ & $169(57)$ & $9(18)$ & $37(80)$ \\
\hline 1984 & $329(82)$ & $305(78)$ & $26(55)$ & $149(49)$ & $82(79)$ & $9(90)$ \\
\hline 1989 & $249(83)$ & $277(84) \ddagger$ & $83(60)$ & $152(51)$ & $47(75)$ & $18(46) t$ \\
\hline $95 \%$ Confidence interval $\$$ & & 0 to 12 & & & & -68 to -20 \\
\hline
\end{tabular}

${ }^{\star}$ Numbers (percentage) responding to question on dangers of drugs: 1969, 238/471 (51); 1974, 331/523 (63); 1979, $519 / 648(80) ; 1984,387 / 540(72)$; and $1989,326 / 380(86)$. Numbers (percentage) responding on how drugs are taken: $1969,439 / 471(93) ; 1974,437 / 523(84) ; 1979,597 / 648(92) ; 1984,509 / 540(94)$; and $1989,362 / 380(95)$.

tChange between 1984 and 1989 significant at $\mathrm{p}<0.01$.

$\ddagger$ Change between 1984 and 1989 significant at $\mathrm{p}<0.05$.

For change in percentage between 1984 and 1989.

Results-Over the 20 years the proportion of pupils who knew someone taking drugs more than doubled from $15 \%$ (71) to $31 \%(117)$ and the proportion who had been offered drugs almost quadrupled from $5 \%(24)$ to $19 \%$ (72). The changes taking place over the past five years were characterised by an increased knowledge about drugs and the first mention of "crack," a purified form of cocaine, and "ecstasy" (methylenedioxymethamphetamine). Peer influence continued to be given as the prime reason for taking drugs. Over the 20 years, though less often mentioned in 1989, television and newspapers remained the most common source of information.

Conclusions-These results suggest the need for responsible coverage by the mass media and for more effective health and social education programmes to prevent the spread of drug misuse.

\section{Introduction}

In recent years intravenous drug misuse has become a major source of transmission of AIDS. In its report AIDS and Drugs Misuse the Advisory Council on the Misuse of Drugs stated that, "Prevention of drug misuse is now more important than ever before and in the longer run the success or failure of efforts to prevent young people from embarking on a career of drug misuse will have a major effect on our ability to contain the spread of HIV."'

In Wolverhampton young people's knowledge and experience of drugs has been monitored by surveys at five year intervals since 1969. These were carried out to determine what the young people knew about drugs and thus provide a basis for a realistic programme of health education. The follow up surveys in 1974, 1979, and 1984 found appreciable changes in the knowledge and experience of the young people surveyed. ${ }^{2-4} \mathrm{We}$ report the results of the latest (1989) survey.

\section{Subjects and methods}

To ensure consistency and permit valid comparisons the format of the questionnaire was the same as that used in the four previous surveys. The present survey was carried out among 380 pupils aged 14 and 15 of mixed ability in the fourth year of three Wolverhampton secondary schools: one in a socially deprived area, one in a more affluent area, and a third socioeconomically between. The sample size of 380 contrasts sharply with the peak figure of 648 in 1979. Although the sample sizes were determined by the number on the register in the schools and the rates of absenteeism, samples of 500 and 400 will give a power of about $90 \%$ to detect a difference of $10 \%$, assuming proportions of $30 \%$ and a significance of 0.05 .5 In the three schools there were slightly more boys than girls on the register, but the sex ratio among the respondents was unknown 
as the pupils were not asked to state their sex. The questionnaire included open ended and ticked replies (see appendix). The pupils had no prior knowledge of the survey and the staff of the school did not take part directly, the questionnaire being handed out and collected by the researchers. In the early surveys a random subsample of $10 \%$ of the respondents was interviewed, and there was no evidence of pupils having misunderstood what was required of them.

Whereas many surveys ask the respondents directly if they have ever taken drugs, in 1969 the indirect questions, "Do you personally know anyone taking drugs?" and "Have you ever been offered drugs?" were thought more likely to produce reliable answers.

\section{Results}

The sample sizes for the five surveys were 471 , $523,648,540$, and 380 . Although all pupils present answered at least part of the questionnaire, there is evidence from a recent study that the absentee effect leads to an underestimation of numbers exposed to drugs. ${ }^{6}$ The total number on the registers in the three schools in 1989 was 481 , implying an absence rate of $21 \%$. The number on the registers in 1984 was 621 , and the absence rate was $13 \%$. The changes in enrolment are a consequence of political influences and falling birth rates. The 1989 survey was carried out nearer to

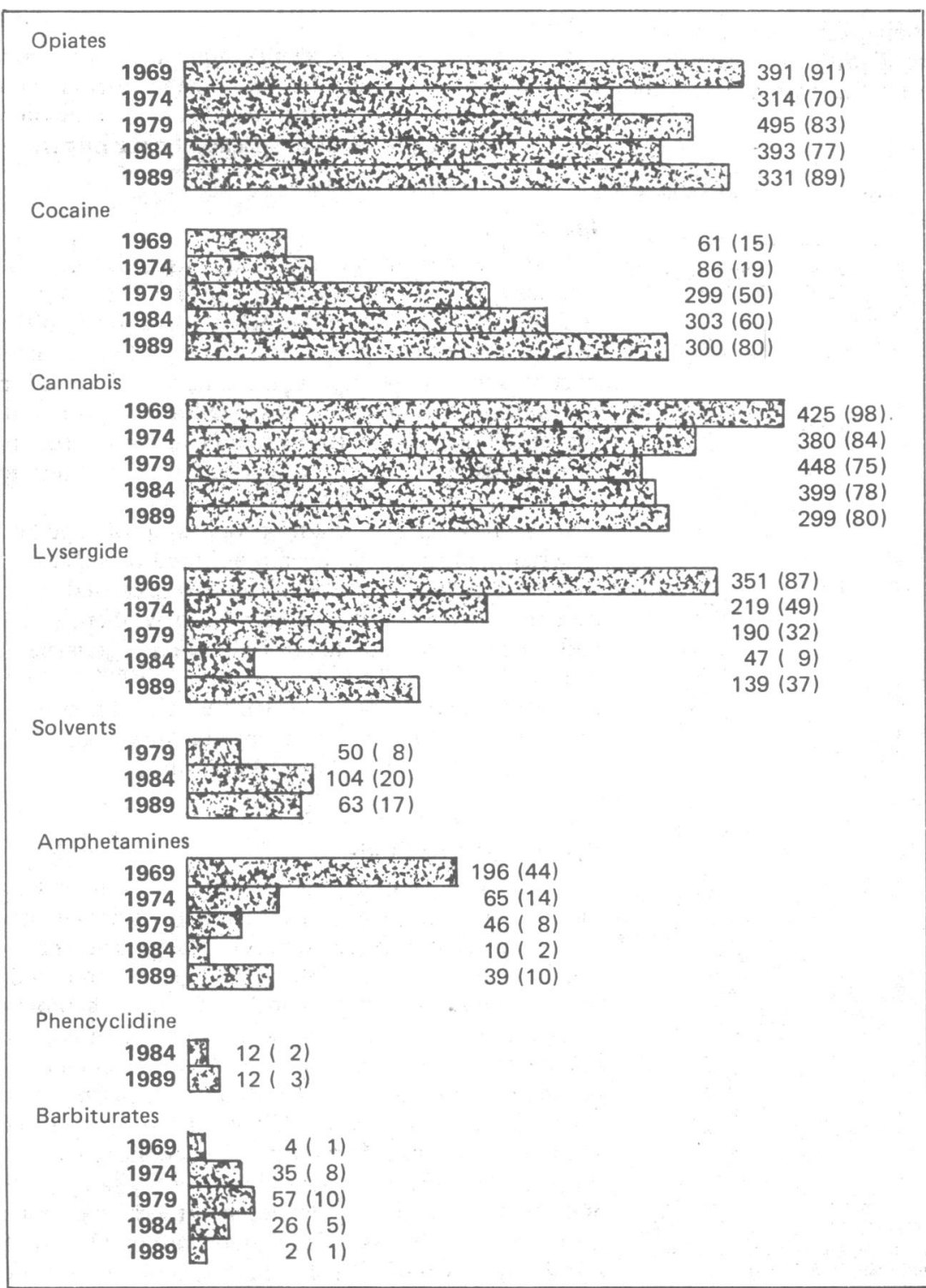

FIG $1-$ Number (\%) of young people who mentioned each drug when asked what drugs were taken by addicts the mid-winter peak for absence due to illness than was the one in 1984. Moreover, it was carried out at a time when the adverse effects of the teachers' industrial action on attendance rates were still being felt.

Roughly similar proportions $(93 \%$ (439) in 1969 $86 \%(450)$ in $1974,92 \%(598)$ in $1979,94 \%(509)$ in 1984, and $98 \%$ (372) in 1989) answered the question, "What drugs taken by addicts do you know?" (Hereafter, whenever comparisons are made in the text the results are listed in the order 1969, 1974, 1979, 1984, and 1989.) Figure 1 shows how the prevalence with which drugs were mentioned changed over the 20 years. With the exception of cannabis, solvents, and phencyclidine hydrochloride all the changes between 1984 and 1989 were significant $(\mathrm{p}<0.01)$. Solvents were mentioned for the first time in 1979 and phencyclidine hydrochloride in 1984. In 1989 both "ecstasy" (methylenedioxymethamphetamine), mentioned by 15 (4\%) of the pupils and "crack," a purified form of cocaine, were mentioned for the first time. "Crack," which was mentioned by $29(8 \%)$ of the pupils, was included in the statistics for cocaine.)

The $86 \%$ of respondents who tried to answer the question, "What dangers do you know of each of these drugs?" represents the highest response rate of the five surveys, which were $51 \%, 63 \%, 80 \%, 72 \%$, and $86 \%$. Table I shows the significant changes between the responses in 1984 and 1989 and the proportions of pupils who correctly specified how the drugs they had mentioned were taken. Data not included in table I show that over the five surveys the response "leads to stronger drugs" was mentioned as a danger on only 29 occasions, 16 of which occurred in 1969 (nine relating to cannabis and seven relating to amphetamines). In 1989 "can kill" and "can cause addiction" were indicated by four and one pupils respectively out of 15 relating to phencyclidine hydrochloride; by five and five pupils respectively out of 15 relating to ecstasy; and by 13 and seven pupils respectively out of 29 relating to crack.

Figure 2 shows the changes over the 20 years in the responses to the two questions, "Do you personally know anyone taking drugs?" and, "Have you ever been offered drugs?" Almost the whole sample replied to both of these questions. The response rates to the first were $97 \%$ (457), 99\% (518), 99\% (642), 99\% (535), and $100 \%$; to the second were $98 \%(462), 99 \%(518), 99 \%$ (642), 99\% (535), and $100 \%$. The change in the proportion of positive replies, $28 \%$ (151) for 1984 and $31 \%$ (117) for 1989 , to the first of these questions was not significant. In $1984,14 \%(75)$ and in $1989,19 \%(72)$ reported that they had been offered drugs, and this difference was just significant $(p \leqslant 0 \cdot 05)$. Analyses of the 1989 data by school showed that in response to the question, "Do you know anyone taking drugs?" $41 \%$ (47) replied positively in the more affluent area compared with $26 \%(22)$ and $27 \%(48)$ in the other two areas. The differences were significant $(p<0 \cdot 05)$. The corresponding figures for the question, "Have you ever been offered drugs?" were $30 \%$ (35), $13 \%$ (11), and $14 \%(26)$, and the differences were highly significant $(\mathrm{p}<0.01)$.

There was a slightly higher response rate in 1989 to the supplementary questions reported in table II. Analyses of school to school differences on the question, "Where were the drugs offered?" were carried out, two groups of pupils being compared. The first group was from the more affluent area, the remainder comprising the second group. Of the pupils who had been offered drugs and had also stated where, half were from the school in the more affluent area, including 16 out of the 19 who mentioned "party" as a source. The difference between the two groups was significant $(p<0 \cdot 01)$. There was also a significant difference but in a different direction for "street": 14 of 


\begin{tabular}{|c|c|c|c|c|c|c|c|c|c|c|c|c|}
\hline & $\begin{array}{c}1969 \\
(n=471)\end{array}$ & $\begin{array}{c}1974 \\
(\mathrm{n}=523) \\
\end{array}$ & $\begin{array}{c}1979 \\
(n=648) \\
\end{array}$ & $\begin{array}{c}1984 \\
(\mathrm{n}=540) \\
\end{array}$ & $\begin{array}{c}1989 \\
(\mathrm{n}=380) \\
\end{array}$ & $\begin{array}{l}95 \% \\
\text { Confidence interval } \\
\end{array}$ & $\begin{array}{c}1969 \\
(n=471) \\
\end{array}$ & $\begin{array}{c}1974 \\
(\mathrm{n}=523) \\
\end{array}$ & $\begin{array}{c}1979 \\
(\mathrm{n}=648) \\
\end{array}$ & $\begin{array}{c}1984 \\
(n=540) \\
\end{array}$ & $\begin{array}{c}1989 \\
(\mathrm{n}=380) \\
\end{array}$ & $\begin{array}{l}95 \% \\
\text { Confidence interval }{ }^{\star}\end{array}$ \\
\hline \multicolumn{7}{|c|}{ What drugs did people take? } & \multicolumn{6}{|c|}{ What drugs have you been offered? } \\
\hline $\begin{array}{l}\text { Cannabis } \\
\text { Solvents }\end{array}$ & $6(24)$ & $29(81)$ & $\begin{array}{r}71(76) \\
1(1)\end{array}$ & $\begin{array}{l}85(60) \\
29(21)\end{array}$ & $\begin{array}{r}78(74) \dagger \\
8(8) \neq\end{array}$ & $\begin{array}{c}2 \text { to } 26 \\
-21 \text { to }-5\end{array}$ & $6(55)$ & $13(56)$ & $\begin{array}{r}36(82) \\
2(5)\end{array}$ & $\begin{array}{l}34(48) \\
15(21)\end{array}$ & $\begin{array}{r}60(92) \ddagger \\
1\end{array}$ & $\begin{array}{c}31 \text { to } 58 \\
-30 \text { to }-10\end{array}$ \\
\hline Opiates & $7(28)$ & $4(11)$ & $12(13)$ & $12(9)$ & $5(5)$ & & & $4(17)$ & $3(7)$ & $4(6)$ & $1(2)$ & \\
\hline Barbiturates & & 26 & $2(2)$ & $10(7)$ & & & & $1(4)$ & $2(5)$ & $3(4)$ & 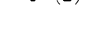 & \\
\hline Cocaine & & & 11 & $5(4)$ & $7(7)$ & & & & 1 (2) & $3(4)$ & & \\
\hline Amphetamines & $16(64)$ & $11(31)$ & $12(13)$ & $2(1)$ & $2(2)$ & & $6(55)$ & $5(22)$ & $6(14)$ & $3(4)$ & & \\
\hline Lysergide & 28 & $6(17)$ & $3(3)$ & $3(2)$ & $3(3)$ & & & $1(4)$ & & $2(3)$ & $2(3)$ & \\
\hline \multirow[t]{2}{*}{ No $(\%)$ of respondents } & $25 \quad 5)$ & $36(7)$ & $94(15)$ & $141(26)$ & $105(28)$ & & $11(2)$ & $23(4)$ & $44(7)$ & $71(13)$ & $65(17)$ & \\
\hline & \multicolumn{4}{|c|}{ Where did they get them? } & & & \multicolumn{6}{|c|}{ Where were they offered? } \\
\hline Street & & $10(12)$ & $27(26)$ & $35(30)$ & $40(40)$ & & $3(14)$ & $11(32)$ & $21(43)$ & $35(50)$ & $38(56)$ & \\
\hline Party & $17(34)$ & $21(25)$ & $32(31)$ & $31(27)$ & $24(24)$ & & $9(41)$ & $16(47)$ & $12(24)$ & $17(24)$ & $19(28)$ & \\
\hline School & $6(12)$ & $10(12)$ & $14(13)$ & $12(10)$ & $13(13)$ & & $6(27)$ & $6(18)$ & $8(16)$ & $10(14)$ & $8(12)$ & \\
\hline Disco & & $4(5)$ & 2928 & 98 & $15(15)$ & & & $3(9)$ & $23(47)$ & $11(16)$ & $10(15)$ & \\
\hline Public house & $7(14)$ & $10(12)$ & 1918 & $20(17)$ & $33(33) \dagger$ & 4 to 28 & & $3(9)$ & $4(8)$ & $2(3)$ & $15(22) \ddagger$ & 9 to 30 \\
\hline Coffee bar & $16(32)$ & 56 & $5(5)$ & $2(2)$ & $1(1)$ & & & $2(6)$ & $1(2)$ & & & (10 \\
\hline No $(\%)$ of respondents & $50(11)$ & $83(16)$ & $104(16)$ & $115(21)$ & $99(26)$ & & $22(5)$ & $34(7)$ & $49 \quad(8)$ & $70(13)$ & $68(18)$ & \\
\hline
\end{tabular}

$\star$ For change in percentages between 1984 and 1989.

†Change between 1984 and 1989 significant at $\mathrm{p}<0.05$.

TABLE III - Reasons given for why young people take drugs. Figures are numbers (percentage) of respondents

\begin{tabular}{lrrrrrr}
\hline & $\begin{array}{c}1969 \\
(\mathrm{n}=471)\end{array}$ & $\begin{array}{c}1974 \\
(\mathrm{n}=523)\end{array}$ & $\begin{array}{c}1979 \\
(\mathrm{n}=648)\end{array}$ & $\begin{array}{c}1984 \\
(\mathrm{n}=540)\end{array}$ & $\begin{array}{c}1989 \\
(\mathrm{n}=380)\end{array}$ & $\begin{array}{c}95 \% \\
\text { Confidence } \\
\text { interval* }\end{array}$ \\
\hline $\begin{array}{l}\text { To feel big, show off, look grown up } \\
\text { Because friends do, trendy }\end{array}$ & $123(29)$ & $145(30)$ & $214(34)$ & $235(47)$ & $180(49)$ & \\
For kicks, for fun, to feel good & $163(39)$ & $122(25)$ & $116(19)$ & $127(25)$ & $126(34) \dagger$ & 3 to 15 \\
To relieve boredom, depression & $90(21)$ & $106(22)$ & $136(22)$ & $52(10)$ & $102(28) \dagger$ & 12 to 23 \\
To escape problems, reality & $24(6)$ & $85(18)$ & $111(18)$ & $30(6)$ & $76(21) \dagger$ & 10 to 19 \\
For the experience, out of curiosity & $81(19)$ & $98(20)$ & $86(14)$ & $41(8)$ & $71(19) \dagger$ & 7 to 16 \\
To calm nerves & $134(32)$ & $61(13)$ & $78(13)$ & 36 & $58(16) \dagger$ & 4 to 13 \\
No(\%) who replied & & $53(11)$ & $133(21)$ & $47(9)$ & $14(4) \dagger$ & -9 to -2 \\
\hline
\end{tabular}

$\star$ For change in percentages between 1984 and 1989.

tChange between 1984 and 1989 significant at $\mathrm{p}<0.01$.

TABLE IV-Replies to question Where did you first hear about drugs? Figures are numbers (percentage) of respondents

\begin{tabular}{|c|c|c|c|c|c|c|}
\hline & $\begin{array}{c}1969 \\
(n=471)\end{array}$ & $\begin{array}{c}1974 \\
(n=523)\end{array}$ & $\begin{array}{c}1979 \\
(n=648)\end{array}$ & $\begin{array}{c}1984 \\
(\mathrm{n}=540)\end{array}$ & $\begin{array}{c}1989 \\
(\mathrm{n}=380)\end{array}$ & $\begin{array}{c}95 \% \\
\text { Confidence interval }\end{array}$ \\
\hline Television & $347(75)$ & $381(73)$ & $458(71)$ & $418(82)$ & $268(72)+$ & -16 to -4 \\
\hline Newspapers & $200(45)$ & $144(28)$ & $145(23)$ & $140(28)$ & $73(20) t$ & -14 to -2 \\
\hline Friends & $56(12)$ & $53(10)$ & $95(15)$ & $63(12)$ & $79(21) t$ & 4 to 14 \\
\hline Parents & $33(7)$ & $79(15)$ & $88(14)$ & $63(12)$ & $58(16)$ & \\
\hline Talk in school & & $89(17)$ & $73(11)$ & $43(8)$ & $61(16)$ & 3 to 12 \\
\hline Radio & $51(11)$ & 296 & $44(7)$ & 306 & 226 & \\
\hline Books & & $47 \quad(9)$ & $29(5)$ & $25 \quad(5)$ & $17(5)$ & \\
\hline No $\%$ who replied & $460(98)$ & $519(99)$ & $644(99)$ & $508(94)$ & $372(98)$ & \\
\hline
\end{tabular}

${ }^{\star}$ For change in percentages between 1984 and 1989 . †Change between 1984 and 1989 significant at $\mathrm{p}<0.01$.

the 38 were from the first group and 24 from the second $(\mathrm{p}<0.05)$.

The only other significant $(\mathrm{p}<0.05)$ difference between the two groups in this section of the questionnaire related to "disco" as a source of drugs for a person known to the respondent. Whereas 10 out of the 39 respondents from the affluent area ticked disco, only five out of the 60 respondents from the second group indicated this as a source.

Table III shows a continued high response rate to the question, "Why do you think young people take drugs?" Whereas "unemployment" was mentioned specifically in 1984, there was no mention in 1989, though 30 pupils (8\%) made a specific mention of "pushed" (by a pusher). In 1989 there was also an increase in the number who mentioned "family difficulties" as a particular reason for taking drugs. Across the five survey years almost the whole sample answered the question, "Where did you first hear about drugs?" Table IV shows the detailed responses.

\section{Discussion}

These results should be interpreted in the light of social, legal, and medical changes over the past 20 years. Coverage of drug taking by the mass media has $\ddagger$ Change between 1984 and 1989 significant at $p<0.01$.

also changed from the hysterical headlines of the late 1960 s through a more low key approach in the 1970s to greater coverage, particularly in the local press, in the early 1980s of solvents and then opiates. With the concern about AIDS there has been considerable publicity about drugs in the late 1980s. In addition, the government's mass publicity campaigns of 1986 and 1988 highlighted the dangers of injecting drugs. There has also been greater encouragement nationally of preventive and health education programmes. ${ }^{178}$

\section{KNOWLEDGE OF DRUG TAKING}

Figure 1 shows that cannabis (the most widely taken illicit drug), which was the most commonly mentioned drug up to 1984, was replaced in 1989 by opiates, which $89 \%$ (338) of the respondents mentioned. The prevalence of mentioning cocaine increased significantly from $15 \%$ (71) in 1969 to $80 \%$ (304) in 1989. Cocaine has been and is the most rapidly growing drug of abuse in the past few years. Crack was referred to specifically by $8 \%$ (30) of the pupils. Interestingly the 1989 survey was carried out in January and February, shortly before the discovery of crack in Wolverhampton and its subsequent increased media coverage.

Amphetamines, which were of major concern in 1969 (then mentioned by $44 \%$ (207)), became less known with only $2 \%$ (11) of the sample mentioning them in 1984 but have increased significantly to $10 \%$ (42) in 1989. Since the mid-1980s both locally and nationally illicit amphetamine taking has been on the

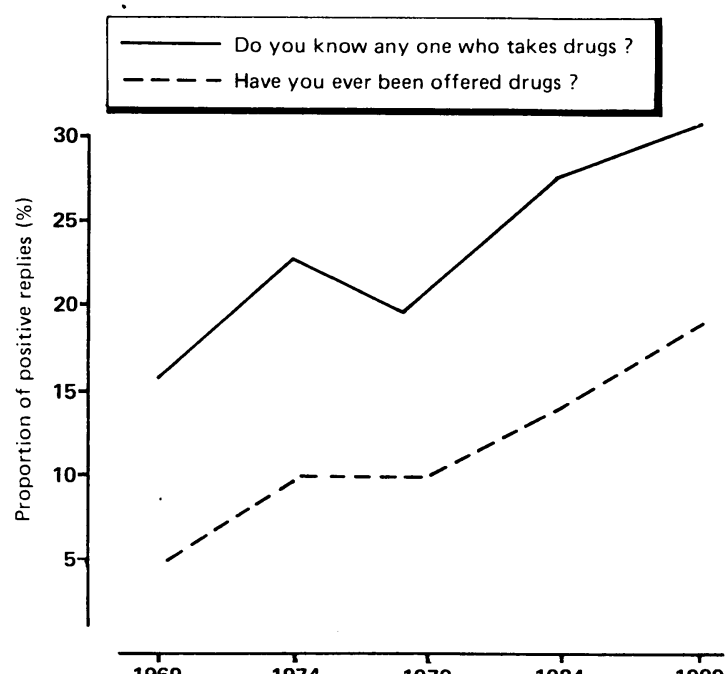

FIG 2-Change in positive responses of young people to two questions over 20 years 
increase. There is concern locally as about half of those taking this drug do so intravenously with consequent hazards. Solvents, which were first mentioned in 1979 by $8 \%(50)$, increased to $20 \%(104)$ in 1984 , and surprisingly the proportion fell to $17 \%(63)$ in 1989 . Despite a death in Wolverhampton in each of the years 1987 and 1988 the local press has given fairly little coverage to solvents, which may explain these figures. Lysergide, however, which was widely taken in the late 1960 s and 1970 s, was mentioned by $87 \%$ (351) in 1969 , fell to $9 \%$ (47) in 1984, and increased significantly to $37 \%$ (139) in 1989. Ecstasy was mentioned for the first time in 1989 (by $4 \%$ (15) of the pupils). These changes reflect both recent media coverage and availability. Some of the changes in press coverage are evident in unpublished statistics on press cuttings made available by the Institute for the Study of Drug Dependence. The numbers of national press cuttings for opiates were 876 in 1986, 501 in 1987, and 221 in 1988. The corresponding figures for cannabis were $298,310,142$; for cocaine 460, 245, 314; and for hallucinogens 20 , 22, 63 .

Table I shows evidence of a more extensive and for the most part more accurate understanding of the dangers of taking various drugs. For example, the proportion of the sample who stated that cocaine can cause dependence doubled in the past five years. The proportion who stated that opiates can kill increased from $32 \%$ (124) to $52 \%(171)$ and that they can cause dependence increased from $16 \%(62)$ to $24 \%$ (79).

Knowledge of the methods by which drugs are taken has steadily increased over the 20 years. The fairly high proportion of correct replies for opiates is again likely to reflect recent publicity.

\section{EXPERIENCE OF DRUG TAKING}

Between 1969 and 1989 the proportion of pupils who knew someone taking drugs more than doubled (from $15 \%$ to $31 \%$ ) and the proportion who had been offered drugs almost quadrupled (from $5 \%$ to $19 \%$ ). These proportions are probably underestimates because of the effect of absenteeism. Consequently a greater proportion of these young people seemed to be at risk of drug taking. The 1989 results show differences between the school in the more affluent area $(41 \%$ for, "Do you know" and 31\% for, "Have you ever been offered") and the other two schools combined (27\% and $14 \%$ respectively for these two questions). Surveys recording those who have ever used drugs also show an increasing prevalence. For example, the proportion was found to be $5 \%$ in a survey by the Office of Population Censuses and Surveys in $1969,{ }^{9} 9 \%$ by Dorn and Thompson in $1973,{ }^{10} 15 \%$ of boys and $11 \%$ of girls by Plant et al in 1979-80 in the Lothian Region, ${ }^{11}$ $25 \%$ by Swadi in 1986 in London, ${ }^{12}$ and $31 \%$ by Newcombe in 1987 on Merseyside. ${ }^{13}$

A study in 1987 by Bean et al in Nottingham reported that $41 \%$ knew someone taking drugs and $19 \%$ had been offered drugs. ${ }^{14}$ A survey carried out in Portsmouth and Havant in 1986 by Brown and Lawton also reported that $41 \%$ of 14 and 15 year olds knew someone who was taking drugs. ${ }^{15}$ Only $5 \%$ of this group admitted having taken drugs, though both the above proportions excluded solvents. This particular study also indicated an increasing exposure with age: $58 \%$ of those aged 16 to 19 indicated that they knew someone who took drugs.

Among the drugs mentioned by those taking drugs and those who had been offered drugs the most commonly mentioned in 1969,1974 , and 1979 were cannabis, amphetamines, and opiates; in 1984 cannabis and solvents; and in 1989 cannabis, solvents, and cocaine (table II). These findings were similar to those in other studies. ${ }^{1216}$ Although only a small proportion of the pupils stated where drugs were offered, the replies reflect the generally increasing importance over the years of the street and public houses as a source of drugs, the variable importance of parties, and not surprisingly the declining importance of coffee bars.

Friends have also been specifically mentioned as a source. Until 1984 these responses taken in conjunction with other evidence ${ }^{17}$ supported the view that those who start taking drugs are first offered them by people they know rather than by strangers. In 1989, however, the increase in the mentioning of "street" and "pub" suggests that there may be other influences at work. An analysis of school to school differences for the 1989 survey yielded some interesting findings in this context. The predominance of parties as a source in the more affluent area might explain the socioeconomic imbalance in the responses referred to above. There was also a significant difference between groups for "street" (in the reverse direction) and for "disco" as a source of drugs for a person known to the respondent. The context in which drugs are encountered seems to depend on social class.

REASONS FOR TAKING AND SOURCES OF INFORMATION ABOUT DRUGS

As in the previous surveys, "To feel big, show off, look grown up" ( $49 \%$ of the respondents) and, "Because friends do, trendy" (34\% of the respondents) were the most commonly mentioned reasons for taking drugs in 1989. Pupils continue to see social and group pressures as possible influences on decisions to take drugs, a view endorsed by other studies. Swadi and Zeitlin stated that, "It seems that peer influence plays a major part in the initiation and the maintenance of adolescent substance using behaviour." 18 "To relieve boredom, depression," fourth in rank order $(21 \%$ of the respondents), was significantly more important, while "to calm nerves" ( $4 \%$ of respondents) has become less important. Also changing significantly between 1984 and 1989 were, "to escape problems," an increase from $8 \%$ to $19 \%$, and "family problems," an increase from $3 \%$ to $9 \%$.

Over the 20 years, though less often mentioned in 1989, television and newspapers have remained the most common source of information. In view of the correlation between press publicity and interest in and possible experimentation with drugs, care must be exercised by producers and editors. At present over sensational coverage could lead to an unhealthy interest in crack and ecstasy. An indirect media effect has also been highlighted by the authors of the qualitative evaluation of the Department of Health and Social Security's Anti drugs-AIDS campaign, who state, "Inevitably, the successful stigmatisation of heroin has allowed other drugs to seem less harmful . . . and seemingly innocuous and recreational."

The proportion who ticked, "Talk in school" doubled in the past five years, and the significant increase in the mention of friends as a source of information (from $12 \%$ to $21 \%$ ) underlines the need for young people to be equipped with accurate information in view of the importance of peer group influence. Over the 20 years parents would seem to have a limited role. A commitment by local education authorities through their drug education coordinators could do much, not only to encourage drug education programmes in schools but also to promote education for teachers and parents.

\section{CONCLUSIONS}

This survey continues to show that there is considerably increased knowledge of the names of illicit drugs. Although there is an increased awareness of the dangers of drug taking, there remains considerable ignorance and misunderstanding. The results also show increasing exposure to drug taking. The 
government's strategy "Tackling drug misuse" suggests action on five main fronts, one of which is "developing prevention." 19 But health education programmes which are effective in preventing drug misuse remain elusive. ${ }^{20-22}$ The complexities of the educational approach have been well stated by Plant $e t$ $a l$, "Education can not be expected to compensate for peer pressure, personal problems, hedonism, biological or psychological predispositions or the widespread availability of cheap psychoactive drugs.": A way forward might be to take the suggestion of Swadi and Zeitlin of peer teaching, which has produced encouraging results in relation to tobacco. ${ }^{23}$ The effectiveness of this approach might be reinforced by the positive encouragement of self esteem in young people even of primary school age. ${ }^{2+}$ More effective health and social education programmes must be

\section{Appendix}

An example of the questionnaire used in all five surveys.

\section{CONFIDENTIAL}

In all answers do NOT count the following as drugs-CIGARETTES, CIGARS, ALCOHOL, MEDICINES

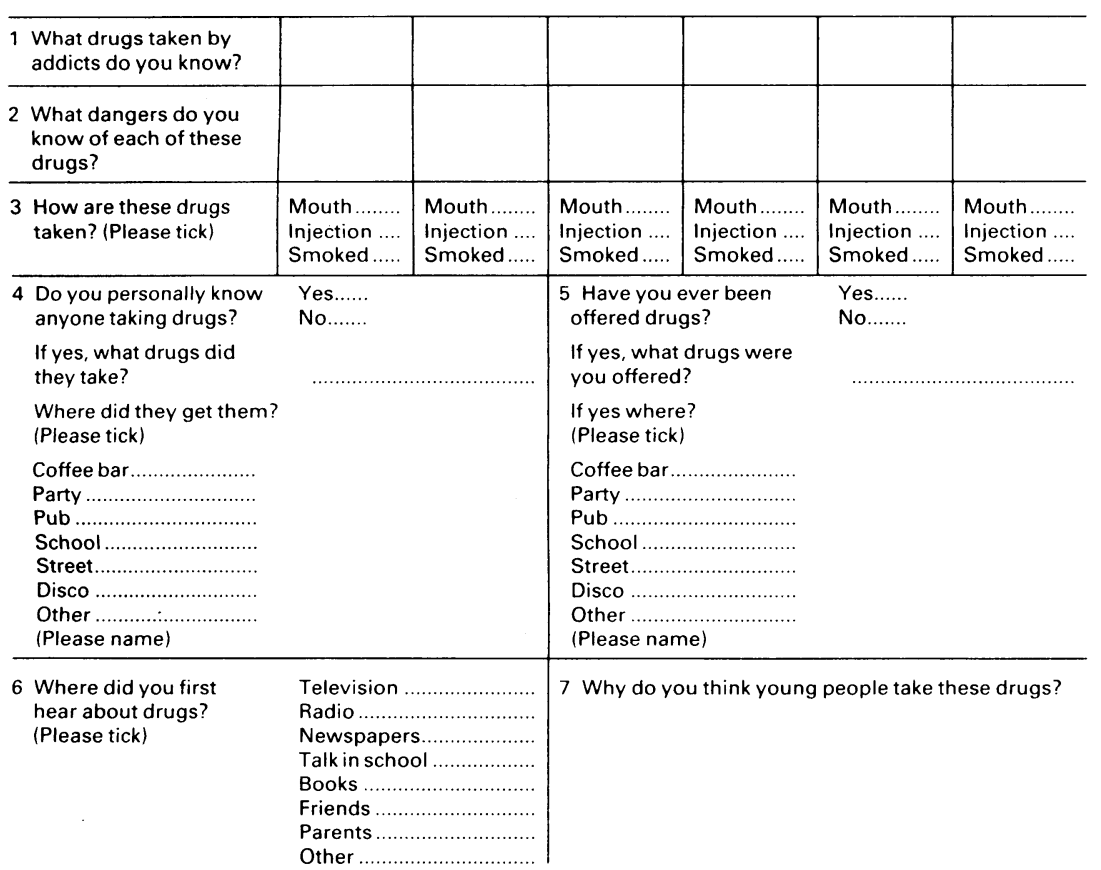

developed from the impetus of the "personal and social education" aspects of the national curriculum.

We thank Mrs S Gentry, Drs J Gurney and K Hackett, Mrs $\mathrm{J}$ Hayes, Mr D Hoque, Mrs M Mallinson, Mr R Morris, Mr $P$ Tilstone, and the three schools taking part for their invaluable help. Being visually handicapped, JDW wishes to thank the express reading service of the Royal National Institute for the Blind, who read many of the reference articles on to tape.

1 Department of Health and Social Security. AIDS and drug misuse. Part 1. London: HMSO, 1988.

2 Wright JD. Knowledge and experience of young people regarding drug abuse between 1969 and 1974. Med Sci Law 1976;16:252-63.

3 Wright JD. Pearl L. Knowledge and experience of young people regarding drug abuse between 1969 and 1979. Br Med f 1981;282:793-6.

4 Wright JD, Pearl L. Knowledge and experience of young people regarding drug abuse between 1969 and 1984 . Br Med 7 1986:292:179-82.

5 Davis OL. Design and analysis of industrial experiments. London: Longman, 1978.

6 Cooke BRB, Evans DA, Farrow SC. Solvent misuse in secondary school children-a prevalence study. Community Med 1988;10:8-13.

7 Department of Health and Social Security. Heroin misuse campaign evaluation. Report of findings - stages I-VI. London: DHSS, 1988

8 Department of Health and Social Security. Anti drugs-AIDS campaign. RS2299. Qualitative evaluation. London: DHSS, 1988.

9 Office of Population Censuses and Surveys. Public attitudes to drug taking. London: HMSO, 1973.

10 Dorn N, Thompson A. A comparison of 1973 and 1974 levels of mid-teenage experimentation with illegal drugs in some schools in England. London: Institute for the Study of Drug Dependence, 1975.

11 Plant MA, Peck DF, Stuart R. The correlates of serious alcohol-related consequences and illicit drug use amongst a cohort of Scottish teenagers. $B r \mathcal{F}$ Addict 1984;79:197-200.

12 Swadi $\mathrm{H}$. Drug and substance use among 3333 London adolescents. Br 7 Addict 1988;83:935-42.

13 Newcombe R. A survey of drug use among young people in South Sefton in 1987 prevalence and risk factors. South Sefton: South Sefton (Merseyside) District Health Authority, 1988

14 Bean PT, Wilkinson CK, Whynes DK, Giggs JA. Knowledge of drugs and consumption of alcohol among Nottingham 15-year-olds. Health Education fournal 1988;47:79-81.

15 Brown C, Lawton J. Illicit drug use in Portsmouth and Havant. London: Policy Studies Institute, 1988.

16 Grube JW, Morgan M. Smoking, drinking and other drug use among Dublin post-primary school pupils. Dublin: Economic and Social Research Institute, 1986.

17 Kandel DB. Epidemiological and psychological perspectives and adolescent drug use. Fournal of the American Academy of Child Psychiatry 1982;21: $328-47$.

18 Swadi $\mathrm{H}$, Zeitlin $\mathrm{H}$. Peer influence and adolescent substance abuse: a promising side? Br $\mathcal{F}$ Addict 1988;83:153-7.

19 Home Office. Tackling drug misuse: a summary of the government's strategy. London: HMSO, 1988.

20 Swadi $\mathrm{H}$, Zeitlin $\mathrm{H}$. Drug education to school children: does it really work? Br f Addict 1987;82:741-6.

21 Plant MA, Peck DF, Samuel E Alcohol, drugs, and school-leavers. London: Tavistock, 1985 .

22 Home Office. Prevention report of the advisory council on the misuse of drugs. London: HMSO, 1984.

23 Health Education Authority. Smoking education for teenagers project. London: Health Education Authority, 1987.

24 Health Education Authority. Health for life. 2. London: Health Education Authority, 1989.

(Accepted 18 October 1989)

\section{ANY QUESTIONS}

\section{Is there any evidence that the artificial sweetener aspartame is a health risk?}

Aspartame is an intense sweetener about 180 times as sweet as sucrose; it is a dipeptide of aspartic acid and the methyl ester of phenylalanine. The material is digested in the small intestine to the amino acid constituents, which are absorbed and metabolised in the normal metabolic pathways. Aspartame is slowly decomposed by heat and extremes of $\mathrm{pH}$ so its use in foods is somewhat restricted. Much evidence from experimental safety testing suggests that the substance is safe, and it was approved for food use in the United Kingdom in 1983. Clearly it is not appropriate for those with phenylketonuria, but regulating authorities in both the United Kingdom and the United States regarded it as safe for normal individuals. It was recognised, however, that use of the sweetener in soft drinks could lead to high consumption by children especially in hot weather, and its use was controlled using an acceptable daily intake of $40 \mathrm{mg}$ per $\mathrm{kg}$ body weight a day. At these levels the amino acids from aspartame would provide only a small percentage of the total intake of these amino acids from protein intake.

The publicised anxieties relate to postulated effects on neurotransmitter synthesis, ' and some critical papers have claimed neurological symptoms and seizures in rats, with possible implications for epileptics. ${ }^{2}$ The evidence has been reviewed extensively by the Food and Drug Administration in the United States, which found it not convincing. Another criticism is that interference with serotonin information would lead to an enhanced appetite for carbohydrate so that the beneficial effects of a low energy sweetener would be lost. There is some evidence that satiety after aspartame is such as to encourage further food consumption. ${ }^{3}$ There is, however, no convincing evidence that there is a specific health risk, only that in controlling energy intakes it may not be sufficient to rely on intense sweeteners, but this is not new. - D A T SOUTHGATE, head, nutrition and food quality department, Agricultural and Food Research Council's Institute of Food Research, Norwich

Yokogoshi H, Roberts $\mathrm{CH}$, Caballers B, Wurtman RJ. Effects of aspartame and glucose administration on brain and plasma levels of large neutral amino acids and brain. 5-hydroxyindoles. Am f Clin Nutr 1984;40:1-7

2 Wurtman RJ. Aspartame: possible effects on seizure susceptibility. Lancet 1985; ii: 1059

Blundell JE, Rogers PJ, Hill AJ. Artificial sweeteners and appetite in man. In: Birch GG, Lindley MG, eds. Low calorie products. London: Elsevier Applied Science, 1988:147-70. 